\title{
Empowering Whistleblowers: How United States Qui Tam Provisions Can Be Used in Malaysia
}

\section{Hazlina Shaik Md Noor Alam*}

Faculty of Law, National University Malaysia, Malaysia

*Corrosponding author's Email: hazlinashaik@ukm.edu.my

Peer-review under responsibility of $4^{\text {th }}$ Asia International Conference 2018 editorial board (http://www.utm.my/asia/our-team/) (C) 2018 Published by Readers Insight Publisher, lat 306 Savoy Residencia, Block 3 F11/1,44000 Islamabad. Pakistan, info@readersinsight.net This is an open access article under the CC BY-NC-ND license (http://creativecommons.org/licenses/by-nc-nd/4.0/). 


\section{Research High Iights}

Whistleblowing, once seen as a negative connotation, has now been embraced as a tool in order to uncover and combat misconduct. Those who partake in this endeavour are known as whistleblowers. Whistleblowers reveal wrongdoings within an institution to the public or to those who hold positions of authority. Whistleblowers ensure that these institutions be held accountable for their wrongful actions, as though there are laws to punish corporate wrongdoings, it might be useless if the wrongful acts are not discovered in the first place. (Oransky, 2018). With whistleblowing, this could help in almost guaranteeing that corporate misconduct would not go unpunished.To blow the whistle is never an easy decision to make, as there are risks of detrimental actions, or worse, againts the whistleblowers. (Westervelt, 2018). Hence, the introduction of whistleblower rewards would dull the sting of backlash, as well as ensuring that deserving whistleblowers receive the compensation that they deserve.

\section{Research Objectives}

Whistleblowers could play an important part in exposing the various unsavory elements in institutions. Whistleblowing would serve a dual purpose, by exposing the wrongdoings of the corporation; it protects those who are in the corporation itself, as well as the society as a whole. (Jones, 2016) . The term whistleblower actually originated from Victorian England whereby, when a crime was committed, the policemen, or as they are more commonly known, the 'bobbies', would blow the whistle while chasing the criminals to alert the public of the crime. (Berk, 2011). The term 'whistleblowing' is becoming more and more commonplace. However, proper understanding as to what would constitute as whistleblowing is still needed. (King, 1999).

\section{Methodology}

This study will employ several methodologies that are inter-related. These include historical method, where the history of whistleblowing will be carefully studied, in order to determine 


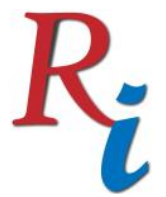

\section{Asia Proceedings of Social Sciences (APSS) \\ www.readersinsight.net/APSS}

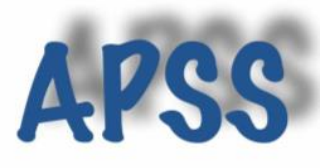

how it came about and where it originated. An analysis will also be done to see how early whistleblowers were treated. In addition, the hardships, if any, that they or those related to them faced would also be examined. This will involve a critical study of the evolution of whistleblowing, from its early application in the areas to its extension in other specific areas, such as whistleblowers protection, its role in exposing wrongdoings as well as rewards and compensation. A jurisprudential analysis would involve an examination of the jurisprudential beginning for whistleblowing. The application of whistleblowing to other specific areas can only be justified on a jurisprudential basis, in that by using case law as the basis for the doctrinal analysis. This is especially relevant when looking at the possible doctrinal limits to the duty of confidentiality.

\section{Results}

Although whistleblowers make disclosures as per their moral duty, by rewarding them, it becomes more than a compensation, it is a gesture that the noble work that they are doing is recognised.

Hence, a study of all the legislations in US and UK, together with the WPA 2010 Act is inevitably comparative in order to see if there are any flaws, and if so, what we can do to avoid them in the near future.

\section{Findings}

It is undeniable that the WPA 2010 were inspired by the legislative experience of US and UK in dealing with the difficult question of whistleblowing and whistleblower protection. As such, certain provisions in these Acts would provide much needed guidance for WPA 2010, especially for qui tam provisions in the US, in the area of whistleblowers rewards. 


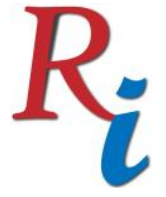

Asia Proceedings of Social Sciences

(APSS)

www.readersinsight.net/APSS

\section{Acknowledgement}

This work is supported by Universiti Kebangsaan Malaysia under GGPM-2018-020

\section{References}

Berk, Steven, 2011, "Whistleblowers-From Victorian England to Dodd Frank", http://www.thecorporateobserver.com/2011/03/articles/consumerprotection/whistleblowers-from-victorian-england-to-dodd-frank/, (accessed on 19 November, 2018).

Jones, Aled, 2016, The Role of Employee Whistleblowing and Raising Concerns in an Organizational Learning Culture - Elusive and Laudable?, International Journal Health Policy Management, Volume 5(1), pp. 67-69.

King, Granville, 1999, “The Implications of An Organization's Culture on Whistleblowing”, Journal of Business Ethics, Volume 20, No 4, p. 325.

Westervelt, Eric, 2018, For Veterans Affairs Whistleblowers, a Culture of Fear and Retaliation, http://www.wbur.org/npr/601127245/for-va-whistleblowers-aculture-of-fear-and-retaliation, 21 Jun 2018, (accessed on 18 November, 2018).

Oransky, Ivan, 2018, How institutions gaslight whistleblowers and what can be done, 30 July, https://retractionwatch.com/2018/07/30/how-institutions-gaslightwhistleblowers-and-what-can-be-done/, (accessed on 18 November, 2018). 